\title{
Mistreatment in an academic setting and medical students' perceptions about their course in São Paulo, Brazil: a cross-sectional study
}

\author{
Maus-tratos em um ambiente acadêmico e percepção sobre o curso entre \\ estudantes de medicina em São Paulo, Brasil: um estudo transversal
} Maria Fernanda Tourinho Peres', Fernanda Babler", Juliana Naomy Lacerda Arakaki", Irene Yamamoto do Vale Quaresma",
Abraão Deyvid Alves de Lima Barreto", Andréa Tenório Correia da Silval"', José Eluf-Neto'v

Department of Preventive Medicine, Faculdade de Medicina da Universidade de São Paulo (FMUSP), São Paulo, SP, Brazil

MD, MSc, PhD. Professor, Department of Preventive Medicine, Faculdade de Medicina da Universidade de São Paulo (FMUSP), São Paulo, SP, Brazil.

"Medical Student, Undergraduate Research Training Program, Department of Preventive Medicine, Faculdade de Medicina da Universidade de São Paulo (FMUSP), São Paulo, SP, Brazil.

"'MD, MSc. Doctoral Student, Postgraduate Program on Preventive Medicine, Department of Preventive Medicine, Faculdade de Medicina da Universidade de São Paulo (FMUSP), São Paulo, SP, Brazil.

"MD, MSc, PhD. Full Professor, Department of Preventive Medicine, Faculdade de Medicina da Universidade de São Paulo (FMUSP), São Paulo, SP, Brazil.

\section{KEY WORDS:}

Human rights abuses.

Aggression.

Social behavior.

Bullying.

Students, medical.

Education, medical.

\section{PALAVRAS-CHAVE:}

Violações dos direitos humanos.

Agressão.

Comportamento social.

Bullying.

Estudantes de medicina.

Educação médica.

\begin{abstract}
CONTEXT AND OBJECTIVE: High prevalence of mistreatment among medical students has been described in the worldwide literature since the 1980s. However, studies addressing the severity and recurrence of victimization and its effects on students' perceptions of their medical course are scarce. This study had the aim of estimating the prevalence of exposure to mistreatment that was considered to be severe and recurrent and its association with medical students' perceptions about their medical course.

METHODS: A cross-sectional study was conducted in a medical school in São Paulo, Brazil. Three hundred and seventeen students from the first to the sixth year answered the online questionnaire.

RESULTS: High prevalence of mistreatment during the course was found. Two thirds of the students considered the episodes to be severe, and around one third reported experiencing recurrent victimization. Occurences of mistreatment that the students considered to be severe were correlated with feeling overloaded and wanting to abandon the medical course.

CONCLUSIONS: Occurrences of mistreatment within the academic environment are frequent in Brazil. The results suggest that mistreatment that was considered to be severe might negatively affect students' perceptions about their course.
\end{abstract}

\section{RESUMO}

CONTEXTO E OBJETIVO: Altas prevalências de maus-tratos entre estudantes de medicina vêm sendo descritas na literatura internacional desde a década de 1980. Estudos sobre a gravidade e recorrência da vitimização e seus efeitos na percepção dos alunos sobre o curso médico são escassos. Este estudo tem por objetivo estimar a prevalência de exposição a maus-tratos considerados graves e recorrentes e sua associação com a percepção dos estudantes de medicina sobre o curso médico.

MÉTODOS: Estudo transversal realizado em uma escola médica em São Paulo, Brasil. Trezentos e dezessete estudantes do primeiro ao sexto ano responderam ao questionário online.

RESULTADOS: Foram encontradas altas prevalências de maus-tratos durante o curso. Dois terços dos estudantes consideraram os maus-tratos graves e cerca de um terço referiu vitimização recorrente. A ocorrência de maus-tratos considerados graves pelos estudantes esteve associada a sentimento de sobrecarga e desejo de abandonar o curso médico.

CONCLUSÃO: A ocorrência de maus-tratos no ambiente acadêmico é frequente no Brasil. Os resultados sugerem que os maus-tratos percebidos como graves podem afetar negativamente a percepção dos estudantes sobre o curso. 


\section{INTRODUCTION}

The high prevalence of mistreatment towards medical students has been identified as an important issue in medical education since the late 1980s and early 1990s. Since that time, studies conducted in different countries ${ }^{1-13}$ have corroborated the high prevalence of different forms of aggression within medical education, thus giving support to the idea that these abusive situations reflect a strongly hierarchical medical culture. ${ }^{14}$

Even though this problem was first described in the late 1980s, the prevalence of abuse, harassment and mistreatment among medical students remains high in different countries. Considering only studies that focused on the concept of bullying and thus limited their analysis to situations that were repetitive and persistent, the prevalence has ranged from $19.7 \%$ in Colombia $^{8}$ to $52 \%$ in Pakistan. ${ }^{6}$ Studies that used broader concepts, including harassment, belittlement, discrimination and abuse not limited to persistent and chronic situations, have found higher prevalence rates: $18.9 \%,{ }^{4}$ approximately $40 \%{ }^{2,5}$ and more than $90 \%{ }^{1,3,12}$

Studies conducted in the US by Sheehan et al. ${ }^{15}$ and Rosenberg ${ }^{16}$ brought to light not only the high prevalence of mistreatment but also its negative consequences for academic achievement and later professional conduct. Although the effects on students' mental health, wellbeing and perceptions about medical education and academic achievements are well known, ${ }^{5,7,12,16-}$ ${ }^{20}$ studies addressing the perceived severity and recurrence of mistreatment and the association with students' perceptions about their medical course are scarce. Most of the studies have been conducted in the US, and no data are available for Brazil.

Medical courses in Brazil have a minimum duration of six years. Basic science disciplines are usually provided in the first two years, and disciplines focusing on training for general medical practice and medical specialties in the third and fourth years. Internship, i.e. the mandatory clinical training period, takes place in the last two years, with activities within healthcare services. In Brazil, students start medical education earlier; medical education may be the first undergraduate course and may immediately follow the secondary school cycle. Thus, medical education can start as early as the ages of 17 or 18 years, with no previous university or college experience. Exposure to different forms of mistreatment within the academic environment at such an early age can have an even more pronounced negative impact, especially in cases that are recurrent or that students consider important. Our hypothesis was that mistreatment that was perceived as severe or recurrent was associated with a negative impact on the way in which students perceive medical education and their academic achievements.

\section{OBJECTIVE}

Our aim was to estimate the prevalence of mistreatment that was perceived as severe and recurrent among medical students and to investigate the association with medical students' perceptions about their medical course.

\section{METHODS}

\section{Study design and participants}

The QUARA project (Quality of Relationships in the Academic Environment) was a cross-sectional study undertaken in a Brazilian public medical school in the city of São Paulo from September to December 2013 that evaluated medical students with regard to the following: mistreatment, socioeconomic characteristics, aspects of the medical course, mental health problems before starting the medical course, lifestyle habits, depression, burnout, social support, quality of life, stressful life events and professional conduct.

All the medical students who were formally registered in 2013 in the same medical school $(\mathrm{n}=1,072)$ were invited to participate in the study, through an initial email containing a link to an informed consent statement and the full questionnaire. Weekly reminders followed the initial email invitation. Additional awareness-raising initiatives included face-to-face reminders during lectures by a student reference group, Facebook posts and distribution of flyers.

\section{Procedures}

To facilitate data collection, an online questionnaire was created using REDCap (Research Electronic Data Capture). ${ }^{21} \mathrm{~A}$ pilot study was conducted $(\mathrm{n}=10)$ before the beginning of data collection in order to test the procedures and identify unclear questions. Authorization for translation and use of the questionnaire Perception of Medical Students on their Learning Environment ${ }^{4}$ was obtained from its author.

The ethics committee of the Medical School of the University of São Paulo (FMUSP) approved this research. Privacy and confidentiality were guaranteed for all participants, and all students signed an informed consent form before participation (Ref 345.993, July 31, 2013).

\section{Measurements}

\section{Mistreatment}

The questions about mistreatment were derived from the questionnaire Perception of Medical Students on their Learning Environment ${ }^{4}$ and were translated by two independent translators following three steps: 1) translation into Portuguese, 2) back-translation and 3) group discussion to establish the final version. The validity of the questionnaire was not assessed.

This questionnaire addresses the following types of mistreatment by different perpetrators (professors, students, residents, 
preceptors/supervisors, attending physicians, nurses, other healthcare professionals, patients or their families and others): shouting/yelling, depreciation/humiliation, task assignment with punitive purposes, derogatory comments about the career, racial/religious discrimination, threat of injury, threat of physical harm, sexual harassment and discrimination and physical violence (slap, push, kick or hit). The responses are 1 (never), 2 (rarely; 1-2 times), 3 (sometimes; 3-4 times) and 4 (often; 5 times or more). For this paper, we took exposure to any type of mistreatment to be a binary variable (0: never/rarely/sometimes; or 1: often, 5 times or more). If a student answered "five times or more" for at least one type of mistreatment, this was considered to be recurrent mistreatment.

An additional question assesses how much each of the mistreatments bothered the student. The responses include the following options: 0 (does not apply; was not a victim), 1 (not at all), 2 (a little) and 3 (a lot). For the purpose of our analysis, a binary variable expressing the importance attributed by the students to the mistreatment suffered was recoded as 0 (was not a victim/ not at all, a little) or 1 (a lot). If a student answered "bothered a lot" for at least one type of mistreatment, this was considered to be mistreatment perceived as severe by the student. This variable expresses students' perception, and does not take any external parameter of gravity into consideration.

\section{Perception of medical course}

Four questions addressed the students' perceptions concerning their medical course: 1) Are you satisfied with your professional choice? a) yes or b) no/I don't know; 2) Have you ever considered dropping out of this course? a) no or b) yes, I did in the past/yes, I still think about it; 3) Do you think your academic achievement is excellent, good, fair or poor? a) excellent/good or b) fair/poor; 4) Do you feel overloaded by the activities you perform as part of your course? a) yes or b) no.

\section{Statistical analysis}

All the data analyses were performed using Stata 13.0. The prevalence of exposure to recurrent mistreatment or mistreatment perceived as severe was calculated. The associations that recurrent mistreatment and mistreatment perceived as severe presented in relation to the perception of overload, dissatisfaction with the medical course, willingness to drop out and perception of poor academic achievement were calculated through Poisson regression analysis after adjusting for sex, age, skin color, whether student was admitted to course through the social inclusion policy and school cycle. Poisson regression was the statistical method chosen because this method enables calculation of prevalence ratios and gives better estimates when dealing with high-prevalence outcomes.
The prevalence and prevalence ratios were estimated after ranking adjustments and post-stratification weighting by considering the distribution of all the students in the medical school according to gender and class for the whole sample and according to school cycle. Confidence intervals (95\%) were calculated for all point estimates. The chi-square test was used to test for linear trend according to school cycle.

\section{RESULTS}

Out of the 1,072 students invited, 338 (31.5\%) agreed to participate in the survey. Of these, 317 students completed the interview. Approximately $50 \%$ of the respondents were female. Most participants were 23 years old or older, and the mean age was 22.4 years (standard deviation, $\mathrm{SD}=2.8$ ). White was the skin color most reported. Nearly $45 \%$ of the sample was in the basic science years of medical education, and only $22 \%$ were in the clinical cycle (internship) (Table 1).

The overall prevalence of mistreatment among medical students during their training years was extremely high (92.3\%) (Table 2). Recurrent mistreatment was reported by $30.1 \%$ of the participants, and most students (64.2\%) reported having been exposed to mistreatment that they perceived as severe. The exposure to overall, recurrent and severe mistreatment increased over the duration of the course, with higher prevalence during the clinical years. A significant linear trend was found for severe mistreatment. This probably expresses the cumulative dimension of our measurement, since we asked about occurrences of mistreatment over the duration of the course.

A negative perception of the medical course was common in our sample: $80 \%$ of the students felt overloaded, nearly $20 \%$

Table 1. Characteristics of the participants $(n=317)$. São Paulo, Brazil, 2013

\begin{tabular}{|c|c|c|}
\hline & $\mathrm{n}$ & $\%$ \\
\hline \multicolumn{3}{|l|}{ Sex } \\
\hline Male & 156 & 49.3 \\
\hline Female & 161 & 50.7 \\
\hline \multicolumn{3}{|l|}{ Skin color } \\
\hline Caucasian & 238 & 75.1 \\
\hline Other & 79 & 24.9 \\
\hline \multicolumn{3}{|l|}{ Age (years) } \\
\hline 17 to 23 & 227 & 71.6 \\
\hline Over 23 & 90 & 28.4 \\
\hline \multicolumn{3}{|c|}{$\begin{array}{l}\text { Student was admitted to course through } \\
\text { social inclusion policy for access to university }\end{array}$} \\
\hline Yes & 69 & 21.7 \\
\hline No & 248 & 78.3 \\
\hline \multicolumn{3}{|l|}{ School cycle } \\
\hline Basic (years 1 and 2) & 142 & 44.7 \\
\hline Preclinical (years 3 and 4) & 104 & 32.8 \\
\hline Clinical (years 5 and 6) & 71 & 22.4 \\
\hline
\end{tabular}


reported feeling dissatisfied and nearly $35 \%$ had considered dropping out of their medical course (Table 2). Basic year students presented negative perceptions about the course more frequently. Clinical year students reported having considered dropping out of the course more frequently. No linear trend was found.

Being exposed to recurrent mistreatment (five times or more) was not associated with any of the indicators of negative perception about the course (Table 3 ). However, being exposed to mistreatment that was perceived as severe was associated with higher prevalence of perceived overload and considering dropping out of the course, in both the crude and the adjusted models. Students who were exposed to mistreatment that they perceived as severe felt more overloaded (prevalence ratio, $\mathrm{PR}=1.17 ; 95 \%$ confidence interval, CI: $1.02 ; 1.36)$ and had considered dropping out of the course more frequently than those not exposed ( $\mathrm{PR}=2.15 ; 95 \% \mathrm{CI}: 1.37 ; 3.36)$. The association between mistreatment perceived as severe and dissatisfaction with the course (PR $=1.67 ; 95 \% \mathrm{CI}: 0.94 ; 2.99)$ reached a borderline significant level $(\mathrm{P}=0.07)$.

\section{DISCUSSION}

This was the first study to take a systematic approach towards investigating exposure to recurrent mistreatment and mistreatment perceived as severe and their associations with students' perceptions about their medical course in a Brazilian medical school. Students in their first to sixth year were enrolled, and data were collected using an online system that guaranteed full anonymity and confidentiality. We used a structured questionnaire to measure mistreatment, classified according to frequency and perceived severity.

Participation was not mandatory, and we had a fair response rate $(31.5 \%)$. Our final sample represented $29.45 \%$ of the total original population $(n=317)$. Low response rates seem to be a problem common to many web-based surveys. ${ }^{22,23}$ In an online survey concerning negative experiences during medical education at the University of Göttingen, in Germany, a similar response rate of $32 \%$ was found. ${ }^{10}$ Since participation in our survey was not mandatory, the possibility of selection bias also has to be borne in mind: this might have resulted either in overestimation of our prevalence estimates (since voluntary surveys attract the attention of those more interested in or affected by the topic) or even in underestimation (because the response rates were lower among the students in their clinical years/internship, when occurrences of mistreatment tend to be more frequent).

It is impossible to know whether those who participated in this study were more or less exposed to mistreatment, but our results are consistent with those reported by other studies. Furthermore, our final sample had more women and fewer clinical-year students than a reference population. To address this imbalance, we used post-stratification weighting for sex and

Table 2. Exposure to mistreatment and negative perceptions about the medical course in São Paulo, Brazil, 2013

\begin{tabular}{|c|c|c|c|c|c|c|c|c|c|}
\hline \multirow{3}{*}{ Variable } & \multirow{2}{*}{\multicolumn{2}{|c|}{ Total }} & \multicolumn{6}{|c|}{ School cycle } & \multirow{3}{*}{$\begin{array}{l}\text { P-value linear } \\
\text { trend in } \chi^{2} \text { test }\end{array}$} \\
\hline & & & \multicolumn{2}{|c|}{ Basic } & \multicolumn{2}{|c|}{ Preclinical } & \multicolumn{2}{|c|}{ Clinical } & \\
\hline & $\%$ & $95 \% \mathrm{Cl}$ & $\%$ & $95 \% \mathrm{Cl}$ & $\%$ & $95 \% \mathrm{Cl}$ & $\%$ & $95 \% \mathrm{Cl}$ & \\
\hline \multicolumn{10}{|l|}{ Mistreatment } \\
\hline Overall & 92.3 & $(88.5 ; 94.9)$ & 90.2 & $(83.7 ; 94.3)$ & 91.2 & $(83.2 ; 95.6)$ & 95.7 & $(87.2 ; 98 ; 6)$ & 0.26 \\
\hline Recurrent & 30.1 & $(24.9 ; 35.9)$ & 24.9 & $(18.3 ; 33.0)$ & 28.2 & $(20.2 ; 37.8)$ & 37.2 & $(26.5 ; 49.3)$ & 0.06 \\
\hline Severe & 64.2 & $(58.4 ; 69.6)$ & 57.5 & $(49.0 ; 65.6)$ & 63.8 & $(53.9 ; 72.7)$ & 71.4 & $(59.3 ; 81.1)$ & 0.04 \\
\hline Feeling dissatisfied & 19.6 & $(15.4 ; 24.5)$ & 21.1 & $(15.1 ; 28.7)$ & 16.1 & $(10.0 ; 24.9)$ & 21.5 & $(13.6 ; 32.2)$ & 0.78 \\
\hline Considering dropping out & 34.3 & $(28.9 ; 40.1)$ & 29.1 & $(22.1 ; 37.4)$ & 36.6 & $(27.7 ; 46.6)$ & 37.1 & $(26.4 ; 49.1)$ & 0.15 \\
\hline Poor academic achievement & 43.4 & $(37.8 ; 49.3)$ & 57.8 & $(49.3 ; 65.8)$ & 39.5 & $(30.3 ; 49.5)$ & 32.9 & $(22.9 ; 44.9)$ & 0.08 \\
\hline
\end{tabular}

$\mathrm{Cl}=$ confidence interval.

Table 3. Association between recurrent or severe mistreatment and negative perception about the medical course in São Paulo, Brazil, 2013

\begin{tabular}{|c|c|c|c|c|c|c|c|c|}
\hline & \multicolumn{2}{|c|}{ Feeling overloaded } & \multicolumn{2}{|c|}{ Feeling dissatisfied } & \multicolumn{2}{|c|}{ Willingness to drop out } & \multicolumn{2}{|c|}{ Poor academic achievement } \\
\hline & PR & $95 \% \mathrm{Cl}$ & PR & $95 \% \mathrm{Cl}$ & PR & $95 \% \mathrm{Cl}$ & PR & $95 \% \mathrm{Cl}$ \\
\hline \multicolumn{9}{|c|}{ Recurrent mistreatment } \\
\hline Crude & 1.06 & $(0.94 ; 1.20)$ & 1.14 & $(0.69 ; 1.87)$ & 1.33 & $(0.95 ; 1.86)$ & 1.08 & $(0.81 ; 1.44)$ \\
\hline Adjusted* & 1.08 & $(0.96 ; 1.23)$ & 1.16 & $(0.70 ; 1.92)$ & 1.29 & $(0.92 ; 1.81)$ & 1.14 & $(0.86 ; 1.51)$ \\
\hline \multicolumn{9}{|c|}{ Severe mistreatment } \\
\hline Crude & 1.2 & $(1.04 ; 1.39)$ & 1.67 & $(0.95 ; 2.09)$ & 2.16 & $(1.39 ; 3.36)$ & 1.24 & $(0.92 ; 1.65)$ \\
\hline
\end{tabular}

PR = Poisson logistic regression. Model adjusted for gender, age, skin color, whether student was admitted to course through the social inclusion policy and school cycle; $\mathrm{Cl}=$ confidence interval. 
school year, with adjustments for all point and interval estimates. It is important to note that this was a cross-sectional study, and it was not possible to ascertain whether the mistreatment occurred prior to the development of negative perception about the medical course.

Exposure to mistreatment that was considered severe was positively associated with perceived overload and willingness to drop out of the course. The exposed students reported feeling overwhelmed more frequently than did those who were not exposed, and expressed willingness to drop out of the course more frequently than did those who were not exposed, even after adjusting for potential confounders. These results support our hypothesis that there would be an independent association between exposure to mistreatment that was perceived as severe and negative perceptions about the course.

\section{Prevalence of exposure to violence}

According to our results, nearly every student suffered at least one form of mistreatment during the medical course. The overall prevalence was extremely high, making it evident that this phenomenon is present in the everyday life of students and plays an important role in the academic environment in medical school, within all school cycles. Even when only the cases that were judged to be severe and those that were recurrent (five times or more during the course) were taken into consideration, the prevalence was high. According to our results, exposure to mistreatment became higher as the course progressed, thus reflecting the cumulative dimension of our measurement. We were unable to ascertain the time when mistreatment occurred with any certainty, since our questionnaire asked about experiences at any time during the course. However, the high prevalence found during the basic years reflects exposure during the first two years of medical training, a period when students might be especially vulnerable to the consequences of mistreatment, given that they enter the medical course early in life in Brazil, immediately following high school and with no previous experience of college or university dynamics.

Similar high figures have previously been described in the United States, ${ }^{1,5}$ Chile, ${ }^{3}$ Nigeria ${ }^{12}$ and Germany. ${ }^{10}$ According to Baldwin et al., ${ }^{1} 96.5 \%$ of the students in the fourth and fifth years in 10 medical schools in the United States reported having had exposure to at least one type of mistreatment (assault, harassment or mistreatment) during the course. More recent results reported by Frank et al. ${ }^{5}$ have indicated that the prevalence remains high: $84 \%$ of the students reported having been belittled during the course in a study conducted in 16 US medical schools. In Nigeria, Chile and Germany, the overall prevalences were, respectively, $98.5 \%, 91.5 \%$ and $88 \%$. A recent meta-analysis ${ }^{24}$ reported that the pooled prevalence of harassment and discrimination among medical students was of the order of 59.6\% (95\% CI: $49.2 \%$; 68\%) and that the pooled prevalence of verbal harassment was $68.8 \%$ (95\% CI: 56.6\%; 80.9\%).

Lower prevalence of mistreatment has been reported in relation to episodes of bullying characterized by recurrent violence. In Saudi Arabia, Alzahrani ${ }^{9}$ reported that the prevalence of bullying was $28 \%$ among medical students, whereas in Pakistan, the prevalence was 52\% among sixth-year medical students. ${ }^{6}$ In Colombia, Paredes et al. ${ }^{8}$ reported that the prevalence of bullying was $19.7 \%$. In our study, $30.1 \%$ of the students reported a pattern of repeated exposure to mistreatment ( $>5$ episodes) during the course.

It is noteworthy that such high prevalence persists and is widespread in so many different countries and scenarios. In the early 1990s, following the study published by Sheehan et al., ${ }^{15}$ the high prevalence of assault, abuse and harassment in medical education was brought to light, as was the existence of a cycle of abusive practices that had been incorporated as a "necessary part" of medical education. According to Fried et al., ${ }^{14}$ the high frequency of abuse, mistreatment and other forms of aggression within medical courses demonstrates the existence of a strongly hierarchical medical culture that permeates the relationship between teachers and students, thus perpetuating situations of maltreatment as "rites of passage". According to our data, this pattern of relationship is present starting from the first years of medical education and persists throughout the course. This culture is, according to Kay, ${ }^{25}$ a problem that goes beyond the undergraduate years and persists over time in different spaces of medical training, where attending physicians, supervisors, residents and students reproduce the abuse and mistreatment suffered during the formative years in a cycle that feeds itself.

\section{Consequences of mistreatment on the way students perceive medical education}

The existence of a pattern of relationships based on humiliation and psychological violence, both between students and in teaching relationships, may negatively affect the way in which students perceive medical education and professional choice. ${ }^{5,16,20}$ Our results brought to light that a high proportion of students have negative perceptions about the course, especially during the basic cycle, in which the figures were higher for all indicators except for considering dropping out of the course, which was seen more frequently during the clinical cycle. This may be a reflection of the cumulative dimension of this specific measurement, since we asked whether the students had ever considered dropping out the course. Feeling overloaded, being dissatisfied and having poor academic achievement were all related to the students' experiences and thus these characteristics closely reflect the students' actual experience with the course. In this sense, it is quite 
surprising that in the basic cycle, the figures were of such high magnitude. This can be explained by the early age at which the students started their training in such a hard and demanding course as medical education, with the need to deal with academic stress, the strong hierarchy mentioned previously and occurrences of mistreatment.

It should be noted that according to our results, episodes of mistreatment are not only highly prevalent but also recurrent and are judged to be severe by the students. Our results demonstrate that the mistreatments that the students considered to be severe were associated with negative impressions about the course. Feeling overwhelmed and considering dropping out of the course were seen more frequently among those who judged the mistreatment to be severe, even after adjustment for potential confounders.

Rosenberg ${ }^{16}$ described the negative consequences of mistreatment on academic achievement and subsequent professional conduct in the 1980s. According to these authors, abuse is related to poorer learning, lower self-esteem and lower quality of patient care. Recent studies have indicated that students who have been the victims of abuse, maltreatment or other forms of aggression are more dissatisfied with their career choice, are more likely to consider dropping out and report poorer relationships with teachers. ${ }^{5}$ According to Timm, ${ }^{11}$ students who have been exposed to bullying or harassment find it harder to concentrate and are less satisfied with their career choice. Mistreatment also has consequences for students' mental health. Those who are exposed feel more stressed and depressed, have low self-esteem and are

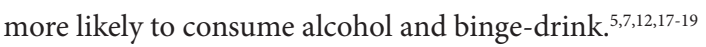

The different sources of stress to which medical students are exposed during their medical training are well known. ${ }^{18,26,27}$ Medical education is hard to access and difficult to sustain, given the large amount of time dedicated to academic activities and the amount of suffering and distress that students need to cope with on a daily basis. Overwhelming activities, along with contact with disease and death early in life, are among the factors that explain the high prevalence of depression and burn-out and the perception of poor quality of life that are commonly reported in medical student surveys. ${ }^{28-34}$

According to Dyrbey et al., ${ }^{35}$ unprofessional conduct and less altruistic professional values are more common among students with burn-out, thus suggesting that distress during medical education may compromise quality of care. Similar results were found in a study involving 1098 medical students in the United States, ${ }^{36}$ in which distress and lack of wellbeing were shown to present connections with lack of empathy among medical students. In the same study, perceptions of personal accomplishment and high quality of life were both associated with higher empathy.
Despite the fact that mistreatment has been found to be highly prevalent in different countries and during different time periods, this study provided the first systematic approach towards this topic in a Brazilian medical school. It should be noted that this is an opportune time to bring this discussion to the forefront in this country, because the new national curriculum guidelines that were recently approved state that medical schools should be able to provide training for doctors to practice "general, humanistic, critical, reflective and ethical medicine (...) with social responsibility and commitment to the defense of citizenship [and] human dignity" ${ }^{37}$ Considering the negative impact of mistreatment on mental health and wellbeing, and the way in which students perceive their course and academic achievements, , $, 7,12,16-20$ occurrences of mistreatment during medical training have high potential to compromise quality of care and the way in which students approach their patients and their suffering. Mistreatment represents an additional source of stress for medical students that should be seriously taken into consideration by medical schools.

\section{CONCLUSION}

Mistreatment is highly prevalent within medical education in Brazil, Mistreatment that is perceived as severe by students has a negative impact on the way in which they perceive their course. In our study, however, recurrent mistreatment per se was not associated with negative perceptions about the course or poor academic achievement.

Our results suggest that the subjective dimension of mistreatment (i.e. the students' perceptions regarding its severity) is more important than recurrence, in considering the impact on the way in which students perceive their course, and this should be taken into considered in future investigations.

\section{REFERENCES}

1. Baldwin DC Jr, Daugherty SR, Eckenfels EJ. Student perceptions of mistreatment and harassment during medical school. A survey of ten United States schools. West J Med. 1991;155(2):140-5.

2. Mangus RS, Hawkins CE, Miller MJ. Prevalence of harassment and discrimination among 1996 medical school graduates: a survey of eight US schools. JAMA. 1998;280(9):851-3.

3. Maida AM, Vásquez $A$, Herskovic V, et al. A report on student abuse during medical training. Med Teach. 2003;25(5):497-501.

4. Rautio A, Sunnari V, Nuutinen M, Laitala M. Mistreatment of university students most common during medical studies. BMC Med Educ. 2005;5:36.

5. Frank E, Carrera JS, Stratton T, Bickel J, Nora LM. Experiences of belittlement and harassment and their correlates among medical students in the United States: Iongitudinal survey. BMJ. 2006;333(7570):682. 
6. Ahmer S, Yousafzai AW, Bhutto N, et al. Bullying of medical students in Pakistan: a cross-sectional questionnaire survey. PLoS One. 2008:3(12):e3889.

7. Heru A, Gagne G, Strong D. Medical student mistreatment results in symptoms of posttraumatic stress. Acad Psychiatry. 2009;33(4):302-6.

8. Paredes OL, Sanabria-Ferrand PA, González-Quevedo LA, Moreno Realphe SP. Bullying en las facultades de medicina colombianas: mito o realidad [Bullying in Colombian medicine faculties: myth or reality]. Rev Med. 2010;18(2):161-72.

9. Alzahrani HA. Bullying among medical students in a Saudi medical school. BMC Res Notes. 2012;5:335.

10. Gágyor I, Hilbert N, Chenot JF, et al. Frequency and perceived severity of negative experiences during medical education in Germany-results of an online-survery of medical students. GMS Z Med Ausbild. 2012;29(4):Doc55

11. Timm A. 'It would not be tolerated in any other profession except medicine': survey reporting on undergraduates' exposure to bullying and harassment in their first placement year. BMJ Open. 2014;4(7):e005140.

12. Owoaje ET, Uchendu OC, Ige OK. Experiences of mistreatment among medical students in a university in south west Nigeria. Niger J Clin Pract. 2012;15(2):214-9.

13. Snadden D. Student health and abuse: what is going on out there? Med Teach. 2003;25(5):461-2.

14. Fried JM, Vermillion M, Parker NH, Uijtdehaage S. Eradicating medical student mistreatment: a longitudinal study of one institution's efforts. Acad Med. 2012;87(9):1191-8.

15. Sheehan $\mathrm{KH}$, Sheehan DV, White K, Leibowitz A, Baldwin DC Jr. A pilot study of medical student'abuse.' Student perceptions of mistreatment and misconduct in medical school. JAMA. 1990;263(4):533-7.

16. Rosenberg DA. Medical student abuse. An unnecessary and preventable cause of stress. JAMA. 1984;251(6):739-42.

17. Richman JA, Flaherty JA, Rospenda KM, Christensen ML. Mental health consequences and correlates of reported medical student abuse. JAMA. 1992;267(5):692-4.

18. Haglund MEM, aan het Rot M, Cooper NS, et al. Resilience in the third year of medical school: a prospective study of the associations between stressful events occurring during clinical rotations and student well-being. Acad Med. 2009;84(2):258-68.

19. Cook AF, Arora VM, Rasinski KA, Curlin FA, Yoon JD. The prevalence of medical student mistreatment and its association with burnout. Acad Med. 2014;89(5):749-54.

20. Haviland MG, Yamagata H, Werner LS, et al. Student mistreatment in medical school and planning a career in academic medicine. Teach Learn Med. 2014;23(3):231-7.

21. Harris PA, Taylor $R$, Thielke $R$, et al. Research electronic data capture (REDCap)--a metadata-driven methodology and workflow process for providing translational research informatics support. J Biomed Inform. 2009:42(2):377-81.
22. Wyatt JC. When to use web-based surveys. J Am Med Inform Assoc. 2000;7(4):426-9.

23. Sheehan KB. E-mail survey response rates: a review. Journal of Computer-Medianted Communication. 2006;6(2). Available from: http://onlinelibrary.wiley.com/doi/10.1111/j.1083-6101.2001. tb00117.x/full. Accessed in 2015 (Nov 13).

24. Fnais N, Soobiah C, Chen MH, et al. Harassment and discrimination in medical training: a systematic review and meta-analysis. Acad Med. 2014;89(5):817-27.

25. Kay J. Traumatic deidealization and the future of medicine. JAMA. 1990;263(4):572-3.

26. West CP, Shanafelt TD. The influence of personal and environmental factors on professionalism in medical education. BMC Med Educ. 2007;7:29

27. Guthrie E, BlackD, Bagalkote H, et al. Psychological stress and burnout in medical students: a five-year prospective longitudinal study. J R Soc Med. 1998;91(5):237-43.

28. Costa EF, Santos SA, Santos AT, Melo EV, Andrade TM. Burnout Syndrome and associated factors among medical students: a crosssectional study. Clinics (Sao Paulo). 2012;67(6):573-80.

29. Dyrbye LN, Thomas MR, Eacker A, et al. Race, ethnicity, and medical student well-being in the United States. Arch Intern Med. 2007;167(19):2103-9.

30. Dyrbye LN, Thomas MR, ShanafeltTD. Systematic review of depression, anxiety, and other indicators of psychological distress among U.S. and Canadian medical students. Acad Med. 2006;81(4):354-73.

31. Goebert D, Thompson D, Takeshita J, et al. Depressive symptoms in medical students and residents: a multischool study. Acad Med. 2009;84(2):236-41.

32. Jamali A, Tofangchiha S, Jamali $R$, et al. Medical students' healthrelated quality of life: roles of social and behavioural factors. Med Educ. 2013;47(10):1001-12.

33. Roberts LW. Understanding depression and distress among medical students. JAMA. 2010;304(11):1231-3.

34. Schwenk TL, Davis L, Wimsatt LA. Depression, stigma, and suicidal ideation in medical students. JAMA. 2010;304(11):1181-90.

35. Dyrbye LN, Massie FS Jr, Eacker A, et al. Relationship between burnout and professional conduct and attitudes among US medical students. JAMA. 2010;304(11):1173-80

36. Thomas MR, Dyrbye LN, Huntington JL, et al. How do distress and well-being relate to medical student empathy? A multicenter study. J Gen Intern Med. 2007;22(2):177-83.

37. Brasil.Ministério daEducação.ConselhoNacional deEducação.Câmara de Educação Superior. Resolução n 3, de 20 de junho de 2014. Institui Diretrizes Curriculares Nacionais do Curso de Graduação em Medicina e dá outras Providências. Available from: http://portal.mec.gov.br/ index.php?option=com_docman\&view=download\&alias=15874-rces003-14\&category_slug=junho-2014-pdf\&ltemid=30192. Acessed in 2015 (Nov 13). 
Source of funding: Fundação de Amparo à Pesquisa do Estado de São

Paulo (FAPESP): research grant no. 2013/11989-3; undergraduate research scholarships from FAPESP (grant nos. 2013/08795-2 and 2013/08788-6); and undergraduate research scholarship from the institutional program for undergraduate research scholarships of the Conselho Nacional de Desenvolvimento Científico e Tecnológico (PIBIC/CNPq)

Conflict of interests: None

Congress: Partial results from this research were presented at the $33^{\text {rd }}$ Medical Congress of the University of São Paulo Medical School (Congresso Médico Universitário da FMUSP, COMU) and at the $52^{\text {nd }}$ Brazilian Congress of Medical Education (Congresso Brasileiro de Educação Médica, COBEM)

Awards received: First place in the Oswaldo Cruz award for clinical medicine, at the $33^{\text {rd }} \mathrm{COMU}$. Second place in the oral presentation category at the $52^{\text {nd }}$ COBEM

Date of first submission: July 3, 2015

Last received: October 9, 2015

Accepted: October 22, 2015

\section{Address for correspondence:}

Maria Fernanda Tourinho Peres

Departamento de Medicina Preventiva da Universidade de São Paulo

Av. Dr. Arnaldo, 455 - sala 2.177

São Paulo — SP — Brasil

CEP 01246-903

Tel. (+55 11) 3061-7444

E-mail:mftperes@usp.br 